\title{
Syringomyelia: A Complication of an Underlying Pathology
}

\author{
Mohammad Sami Walid ${ }^{\mathrm{a}, \mathrm{c}}$, Mazen Sanoufa ${ }^{\mathrm{a}}$, Juan Salvatierra ${ }^{\mathrm{b}}$
}

\begin{abstract}
Patients with syringomyelia may have diverse etiology and experience a variety of symptoms. This report describes two cases of syringomyelia in patients with different profiles, presentations and pathomechanisms.
\end{abstract}

Keywords: Syrigomyelia; Syrinx; Arachnoid cyst; Arnold-Chiari

\section{Introduction}

Syringomyelia (syrinx) is a rare neurological disorder characterized by slowly developing fluid-filled areas that extend longitudinally down the spinal cord causing symptoms such as pain, weakness and stiffness in the back, shoulders, arms, and legs. Syringomyelia has a prevalence of 3.3 to $8.5 / 100,000$ people with some ethnic variability [1-4]. In the United States, syringomyelia is more common in AfricanAmericans than in Caucasians [5]. Patients may have diverse etiology and experience a variety of symptoms. This report describes two cases of syringomyelia in patients with different profiles, presentations and pathomechanisms.

\section{Case 1}

A 67-year-old Caucasian male presents with a history of worsening leg numbness of several years duration. Imaging showed a T4-T8 syrinx. An arachnoidal cyst was suspected

\footnotetext{
Manuscript accepted for publication April 6, 2010

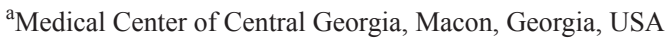

${ }^{\mathrm{b}}$ Mercer University, Macon, Georgia, USA

${ }^{\mathrm{c} C}$ Corresponding author, Email: mswalid@yahoo.com
}

doi:10.4021/jocmr2010.04.291w at $\mathrm{T} 6$ due to the flattening and anterior displacement of the cord immediately under the spinal cord enlargement (Fig. 1). The patient had no remarkable medical history and was on no medications. He denied bowel or bladder symptoms. He smoked cigarettes and drank alcohol daily. Neurological exam was unremarkable except for some decreased sensation to light touch below L1. The patient underwent T4 to $\mathrm{T} 8$ posterior decompression and exploration with removal of arachnoidal cyst and opening of syrinx.

\section{Case 2}

A 12-year-old African-American girl presented with progressively worsening headaches. Neurological exam was unremarkable. Imaging showed a Chiari I deformity (lowlying cerebellar tonsils down to the level of $\mathrm{C} 2$ ) with a huge spinal cord syrinx from C2 to T2 (Fig. 2). Magnetic resonance angiography showed Limited flow through foramen magnum of the cerebrospinal fluid. The patient had posterior fossa craniotomy, C1-2 laminectomy and duraplasty for decompression of Chiari and midline cervical myelotomy for decompression and drainage of cervical syrinx.

\section{Discussion}

Syringomyelia may be related to a congenital malformation or de novo abnormality in the central nervous system. Arachnoid cysts are intra-arachnoid collections of cerebrospinal fluid congenital in origin, however, onset of symptoms may be delayed until adolescence through expansion and pressure on the normal neural tissue leading to obstruction of the cerebrospinal fluid flow and neurological deficit [6]. These cysts may rarely be associated with syringomyelia or compressive myelopathy [7-9]. Spinal arachnoid cyst associated with syringomyelia can be treated by simple excision of the cyst without shunting the syrinx if the decompression effect resulting from removal of the cyst is sufficient [10].

Chiari malformation is another congenital abnormality whereby the cerebrellar tonsils herniate through the foramen magnum into the spinal canal causing disturbance in cere- 


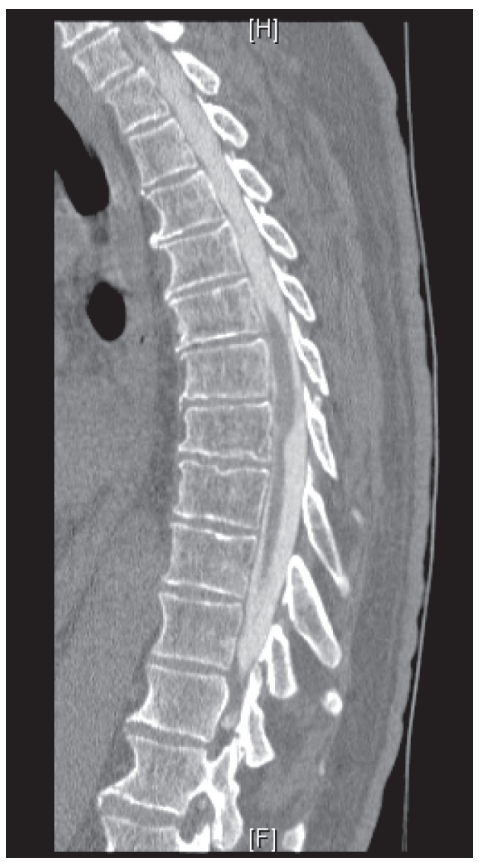

Figure 1. Computed tomography with contrast (a 67-year-old male patient).

brospinal fluid dynamics which may manifest by headaches, double vision, dizziness, and muscle weakness, particularly in the upper extermities. Most cases of non-traumatic syringomyelia occur in association with a Chiari malformation [11]. Very rarely both malformations (arachnoid cyst and Chiari malformation) can exist in a patient with syringomyelia $[12,13]$. In most published cases the syringomyelia

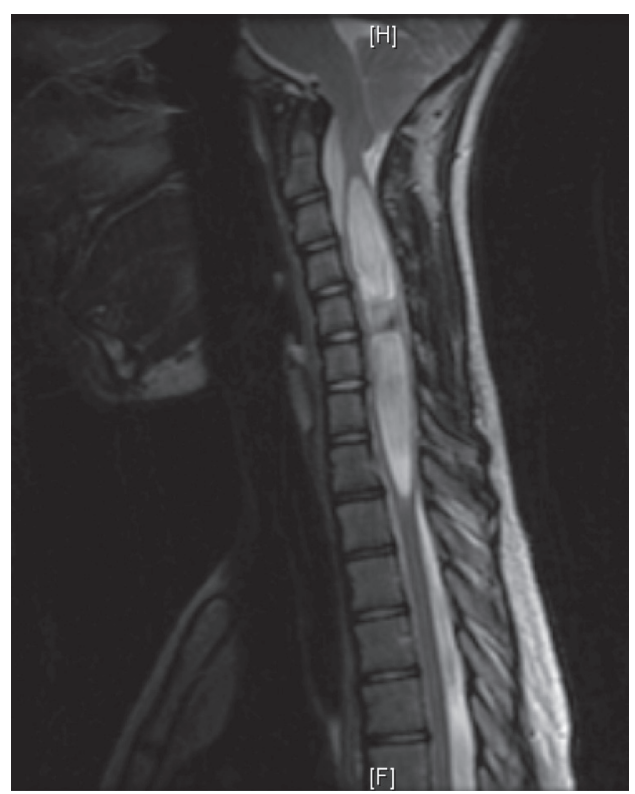

Figure 2. Magnetic resonance T2 image (a 12-year-old female patient). has been attributed to obstruction of cerebrospinal fluid flow at the foramen magnum by the arachnoid cyst itself. Very rarely, a posterior fossa arachnoid cyst may produce tonsillar descent and syringomyelia $[12,14]$.

Syringomyelia can be viewed as a complication of an underlying pathology which may be a simple arachnoid cyst or a complex Chiari malformation. It is important to keep these two entities in mind when dealing with patients expressing symptoms suggestive of progressive myelopathy in all age groups.

\section{References}

1. Brewis M, Poskanzer DC, Rolland C, Miller H. Neurological disease in an English city. Acta Neurol Scand 1966;42(Suppl 24:21-89.

2. Brickell KL, Anderson NE, Charleston AJ, Hope JK, Bok AP, Barber PA. Ethnic differences in syringomyelia in New Zealand. J Neurol Neurosurg Psychiatry 2006;77(8):989-991.

3. Gudmundsson KR. The prevalence of some neurological diseases in Iceland. Acta Neurol Scand 1968;44(1):5769.

4. Kurland LT. Descriptive epidemiology of selected neurologic and myopathic disorders with particular reference to a survey in Rochester, Minnesota. J Chronic Dis 1958;8(4):378-418.

5. Tipton AC, Jr., Haerer AF. Syringomyelia in Mississippi. J Miss State Med Assoc 1970;11(10):533-537.

6. Gelabert-Gonzalez M. [Intracranial arachnoid cysts]. Rev Neurol 2004;39(12):1161-1166.

7. Ergun T, Lakadamyali H. Multiple extradural spinal arachnoid cysts causing diffuse myelomalacia of the spinal cord. Neurologist 2009;15(6):347-350.

8. Kim MS, Kim SH. Syringomyelia associated with a spinal arachnoid cyst. J Korean Neurosurg Soc 2009;45(5):315-317.

9. Kiran NA, Kasliwal MK, Suri A, Mahapatra AK. Giant posterior fossa arachnoid cyst associated with syringomyelia. Clin Neurol Neurosurg.

10. Takeuchi A, Miyamoto K, Sugiyama S, Saitou M, Hosoe H, Shimizu K. Spinal arachnoid cysts associated with syringomyelia: report of two cases and a review of the literature. J Spinal Disord Tech 2003;16(2):207-211.

11. Owler BK, Halmagyi GM, Brennan J, Besser M. Syringomyelia with Chiari malformation; 3 unusual cases with implications for pathogenesis. Acta Neurochir (Wien) 2004;146(10):1137-1143; discussion 1143.

12. Martinez-Lage JF, Almagro MJ, Ros de San Pedro J, Ruiz-Espejo A, Felipe-Murcia M. Regression of syringomyelia and tonsillar herniation after posterior fossa arachnoid cyst excision. Case report and literature review. Neurocirugia (Astur) 2007;18(3):227-231. 
13. Martinez-Lage JF, Ruiz-Espejo A, Guillen-Navarro E, Almagro MJ. Posterior fossa arachnoid cyst, tonsillar herniation, and syringomyelia in trichorhinophalangeal syndrome Type I. J Neurosurg 2008;109(4):746-750.
14. Bauer AM, Mueller DM, Oro JJ. Arachnoid cyst resulting in tonsillar herniation and syringomyelia in a patient with achondroplasia. Case report. Neurosurg Focus 2005;19(5):E14. 